\title{
Analyzing EGFR mutations and their association with clinicopathological characteristics and prognosis of patients with lung adenocarcinoma
}

\author{
XIUZHI ZHOU ${ }^{1,3 *}$, LI CAI $^{2 *}$, JUNJIE LIU $^{3 *}$, XIAOMIN HUA ${ }^{1}$, YING ZHANG ${ }^{3}$, \\ HUILIN ZHAO ${ }^{3}$, BIN WANG $^{1},{\text { BOQING } \mathrm{LI}^{3} \text { and PENGZHOU GAI }}^{2}$
}

${ }^{1}$ Department of Microbiology, Qingdao University, Qingdao, Shandong 266071; ${ }^{2}$ Department of Pathology and Medicine, Yantai Yuhuangding Hospital of Qingdao University, Yantai, Shandong 264000; ${ }^{3}$ School of

Basic Medical Sciences, Binzhou Medical University, Yantai, Shandong 264003, P.R. China

Received September 18, 2017; Accepted March 29, 2018

DOI: $10.3892 / \mathrm{ol} .2018 .8681$

\begin{abstract}
Epidermal growth factor receptor (EGFR) is an important gene in the development of lung adenocarcinoma. However, there is controversy regarding the association between EGFR mutations and survival time of patients with lung adenocarcinoma. In the present study, tissue specimens and clinical data were collected from 219 patients with lung adenocarcinoma who had not undergone prior radiotherapy or chemotherapy. EGFR mutations were detected using a
\end{abstract}

Correspondence to: Professor Bin Wang, Department of Microbiology, Qingdao University, 308 Ningxia Road, Qingdao, Shandong 266071, P.R. China

E-mail: wangbin532@126.com

Dr Pengzhou Gai, Department of Pathology and Medicine, Yantai Yuhuangding Hospital of Qingdao University, 20 Yudong Road, Yantai, Shandong 264000, P.R. China

E-mail: 154413933@163.com

${ }^{*}$ Contributed equally

Abbreviations: EGFR, epidermal growth factor receptor; ARMS, amplification refractory mutation system; CT, computed tomography; F-PCR, fluorescence-polymerase chain reaction; G719X, point mutations in exon 18; 19-Del, deletion mutations in exon 19; 20-Ins, insertion mutations in exon 20; L858R and L861Q, two base-pair substitution mutations in exon 21; MIA, minimally invasive adenocarcinoma; IA, invasive adenocarcinoma; IAV, invasive adenocarcinoma variant; IASLC/ATS/ERS, International Association for the Study of Lung Cancer, American Thoracic Society and European Respiratory Society; MST, median survival time; NSCLC, non-small cell lung cancer; OS, overall survival; pTNM, pathological tumor-node-metastasis; TKIs, tyrosine kinase inhibitors

Key words: lung adenocarcinoma, epidermal growth factor receptor, mutation, clinicopathological characteristics, tyrosine kinase inhibitors, prognosis fluorescence polymerase chain reaction method, and the association between EGFR mutations and clinicopathological characteristics was analyzed. Overall survival (OS) curves were constructed using the Kaplan-Meier method and the influence of clinicopathological characteristics on OS was analyzed using the Cox regression model. The EGFR mutation rate was $50.7 \%$, and the most common mutations were the L858R substitution mutation in exon 21 (L858R; 54.9\%) and the deletion mutation in exon 19 (19-Del; 36\%). The presence of EGFR mutations varied significantly with sex, smoking history, $\mathrm{T}$ stage, vascular invasion and adenocarcinoma subtypes $(\mathrm{P}<0.05)$. The survival time was significantly longer for female, young ( $<60$ years-old), non-smokers or patients exhibiting EGFR mutations (G719X, 19-Del, L858R and L861Q). The survival time was also significantly longer for patients with a 19-Del mutation, early stage tumors, tyrosine kinase inhibitors targeted therapy-treated patients, for those not exhibiting nerve or vascular invasion, and for those without disease recurrence $(\mathrm{P}<0.05)$. Multivariate analysis revealed that tumor pathological Tumor-Node-Metastasis (pTNM) stage, nerve invasion, vascular invasion, EGFR mutation and the 19-Del mutation were independent predictors $(\mathrm{P}<0.05)$. Therefore, tumor pTNM stage, nerve invasion, vascular invasion and EGFR mutation status, particularly that of 19-Del, were independent prognostic factors for patients with lung adenocarcinoma.

\section{Introduction}

With the rapid development of industrialization, lung cancer has become the most common type of malignant tumor, with high rates of morbidity and mortality (1). It has been reported that $>730,000$ cases were diagnosed, and $\sim 610,000$ mortalities due to lung cancer occurred in China in 2015 (2). Non-small cell lung cancer (NSCLC) accounts for $~ 85 \%$ lung cancer cases, and the majority of patients are diagnosed at a late stage of NSCLC, and thus have a poor prognosis (3). Lung adenocarcinoma is the most common subtype of NSCLC, with a high recurrence rate and short survival time (4). According to previous research, oncogenes serve an important role in the 
occurrence and development of lung adenocarcinomas, and may be potential therapeutic targets (4-6).

Epidermal growth factor receptor (EGFR) is an important driving gene in lung adenocarcinoma, and it has been reported that EGFR mutations are more common in Asian patients, non-smokers and females (6). Previous studies have demonstrated that mutation of EGFR is a positive predictor of prognosis for patients with lung adenocarcinoma (7-10). Patients with EGFR mutations have been indicated to respond well to EGFR tyrosine kinase inhibitors (EGFR-TKIs) (11). However, it has been demonstrated that patients with different EGFR mutation subtypes experience different outcomes following EGFR-TKI treatment $(8,12,13)$. Therefore, the association between EGFR mutations and survival time of patients with lung adenocarcinoma requires further investigation. Furthermore, in developing countries with limited economic conditions, including China, EGFR mutations of patients with lung adenocarcinoma often go undetected (14). This highlights the importance of characterizing the significance of EGFR mutations in lung adenocarcinoma and the associated clinicopathological characteristics. The International Association for the Study of Lung Cancer, American Thoracic Society and European Respiratory Society (IASLC/ATS/ERS) classification system (2011 version) is often used to classify lung adenocarcinoma $(13,15)$. However, there is some controversy over its effectiveness (15-17).

Using IASLC/ATS/ERS classification, EGFR mutation detection was performed using tissues from 219 patients with lung adenocarcinoma. The associations between EGFR mutation status and clinical characteristics were analyzed, and the significance was evaluated in the context of survival time to provide empirical and theoretical foundations for the improvement of the clinical treatment of lung cancer.

\section{Materials and methods}

Patients and clinical data. A total of 435 patients with primary lung adenocarcinoma, who underwent surgical resection between October 2012 and March 2013 at the Affliated Hospital of Binzhou Medical University (Yantai, China) or the Yuhuangding Hospital (Yantai, China), were invited to participate in the present study. However, 216 patients were excluded due to the lack of follow-up information or accurate classification following surgery. The final 219 participants included 105 females and 114 males, with a mean age of 60 years (range, 30-88 years).

Biopsy materials were selected in accordance with the National Comprehensive Cancer Network guidelines of 2011 (18). The tissues were classified by 2 experienced pathologists of the Affliated Hospital of Binzhou Medical University (Yantai, China) and the Yuhuangding Hospital (Yantai, China), using the IASLC/ATS/ERS system (19). Pathological Tumor-Node-Metastasis (pTNM) classification was performed according to the international lung cancer staging system (20). Adenocarcinoma subtypes included minimally invasive adenocarcinoma (MIA), invasive adenocarcinoma (IA) and invasive adenocarcinoma variant (IAV).

The present study was approved by the Medical Research Ethics Committee of Binzhou Medical University (Yantai, China), and all patients provided written informed consent for their participation in the present study. No patients had received prior radiotherapy or chemotherapy. The postoperative treatment was as follows: Pemetrexed and cisplatin for patients without EGFR mutations or with mutations in exon 20; the first-line TKI, gefitinib, for patients with 19-Del and L858R mutations, and the second-line TKI, afatinib, for patients with other EGFR mutations. All patients were followed-up by telephone or hospital appointment, including a computed tomography scan of the chest and upper abdomen. Tumor-enlargement or identification of distant metastasis was considered indicative of disease recurrence. Non-smokers were defined as smoking $<100$ cigarettes in lifetime. The final follow-up took place on April 30th, 2017. The overall survival (OS) time was defined as the period from surgery to the last day of follow-up, or the occurrence of mortality.

EGFR mutation detection. All surgical specimens were fixed in formalin and embedded in paraffin. The sample DNA was obtained using a paraffin tissue DNA Extraction kit (cat. no. 56404; Qiagen GmbH, Hilden, Germany). The concentration of DNA was adjusted to $1 \mathrm{ng} / \mu \mathrm{l}$, and EGFR mutations were detected using the amplification refractory mutation system (ARMS) with human EGFR Mutations Detection kit (cat. no. ADx-EG01; Amoy Diagnostics, Co., Ltd., Xiamen, China), and the assay was performed according to the manufacturer's protocol and as previously described (21). In brief, the ARMS-PCR assay was performed in a $50-\mu l$ volume containing $5 \mu \mathrm{l}$ PCR buffer, $10 \mathrm{pM}$ forward and reverse primers, $20 \mathrm{pM}$ probe and $12.5 \mu \mathrm{M}$ dNTPs. The thermocycling conditions were as follows: $95^{\circ} \mathrm{C}$ for $5 \mathrm{~min}$, then 15 cycles of $95^{\circ} \mathrm{C}$ for $25 \mathrm{sec}$, $64^{\circ} \mathrm{C}$ for $20 \mathrm{sec}$ and $72^{\circ} \mathrm{C}$ for $20 \mathrm{sec}$, followed by 31 cycles of $93^{\circ} \mathrm{C}$ for $25 \mathrm{sec}, 60^{\circ} \mathrm{C}$ for $35 \mathrm{sec}$ and $72^{\circ} \mathrm{C}$ for $20 \mathrm{sec}$. The human EGFR Mutations Detection kit is able to detect 29 EGFR mutations from exon 18 to exon 21, including 3-point mutations in exon 18 (G719X), 19 19-Del mutations, 3 insertion mutations in exon 20 (20-Ins), T790M, S768I, L858R, and another base-pair substitution mutation in exon 21 (L861Q).

Statistical analysis. The associations between EGFR mutations and clinical characteristics were analyzed using $\chi^{2}$. OS curves, which were constructed using the Kaplan-Meier method, and further evaluation was performed using the log-rank test. The association between clinical characteristics and OS time was analyzed using Cox regression. All statistical analyses were performed using SPSS software (version 17.0; SPSS Inc., Chicago, IL, USA). $\mathrm{P}<0.05$ was considered to indicate a statistically significant difference.

\section{Results}

Descriptive statistics. The patients' clinical data are presented in Table I. Of the 219 lung adenocarcinoma patients enrolled in the present study, 54 patients $(24.7 \%$ ) were current or former smokers, 171 patients $(78.1 \%)$ had pTNM stage I tumors, 170 patients (77.6\%) had T1 stage tumors, 184 patients $(84 \%)$ were classified with N0 stage lung adenocarcinoma, and 202 patients (92.2\%) were classified with M0 stage lung adenocarcinoma. A total of 29 patients (13.2\%) exhibited nerve invasion, 33 patients $(15.1 \%)$ exhibited vascular invasion and 209 patients (95.4\%) were diagnosed with invasive adenocarcinoma. Following surgery, 
Table I. Associations between EGFR mutation status and clinical characteristics.

\begin{tabular}{|c|c|c|c|c|}
\hline \multirow[b]{2}{*}{ Characteristics } & \multirow[b]{2}{*}{ No. $(\%)$} & \multicolumn{2}{|c|}{ EGFR, number (\%) } & \multirow[b]{2}{*}{ P-value } \\
\hline & & Wild type & Mutation & \\
\hline \multicolumn{5}{|l|}{ Sex } \\
\hline Female & 105 (47.9) & $31(29.5)$ & $74(70.5)$ & \multirow[t]{2}{*}{$<0.001$} \\
\hline Male & $114(52.1)$ & $77(67.5)$ & $37(32.5)$ & \\
\hline \multicolumn{5}{|l|}{ Age, years } \\
\hline$<60$ & $99(45.2)$ & $44(44.4)$ & $55(55.6)$ & \multirow[t]{2}{*}{0.190} \\
\hline$\geq 60$ & $120(54.8)$ & $64(53.3)$ & $56(46.7)$ & \\
\hline \multicolumn{5}{|l|}{ Smoking status } \\
\hline Non-smoker & $165(75.3)$ & $72(43.6)$ & $93(56.4)$ & \multirow[t]{2}{*}{0.003} \\
\hline Smoker & $54(24.7)$ & $36(66.7)$ & $18(33.3)$ & \\
\hline \multicolumn{5}{|l|}{ T stage } \\
\hline $\mathrm{T} 1$ & $170(77.6)$ & $77(45.3)$ & $93(54.7)$ & \multirow[t]{2}{*}{0.027} \\
\hline $\mathrm{T} 2$ & $49(22.4)$ & $31(63.3)$ & $18(36.7)$ & \\
\hline \multicolumn{5}{|l|}{$\mathrm{N}$ stage } \\
\hline No & $184(84.0)$ & $88(47.8)$ & $96(52.2)$ & \multirow[t]{3}{*}{0.540} \\
\hline N1 & $27(12.3)$ & $16(59.3)$ & $11(40.7)$ & \\
\hline $\mathrm{N} 2$ & $8(3.7)$ & $4(50.0)$ & $4(50.0)$ & \\
\hline \multicolumn{5}{|l|}{ M stage } \\
\hline M0 & $202(92.2)$ & $100(49.5)$ & $102(50.5)$ & \multirow[t]{3}{*}{0.856} \\
\hline M1a & $3(1.4)$ & $1(33.3)$ & $2(66.7)$ & \\
\hline M1b & $14(6.4)$ & $7(50.0)$ & $7(50.0)$ & \\
\hline \multicolumn{5}{|l|}{ pTNM stage } \\
\hline I & $171(78.1)$ & $82(48.0)$ & $89(52.0)$ & \multirow[t]{4}{*}{0.607} \\
\hline II & $30(13.7)$ & $17(56.7)$ & $13(43.3)$ & \\
\hline III & $1(0.5)$ & $1(100.0)$ & $0(0.0)$ & \\
\hline IV & $17(7.8)$ & $8(47.1)$ & $9(52.9)$ & \\
\hline \multicolumn{5}{|l|}{ Nerve invasion } \\
\hline No & $190(86.8)$ & $89(46.8)$ & $101(53.2)$ & \multirow[t]{2}{*}{0.061} \\
\hline Yes & $29(13.2)$ & $19(65.5)$ & $10(34.5)$ & \\
\hline \multicolumn{5}{|c|}{ Vascular invasion } \\
\hline No & $186(84.9)$ & $86(46.2)$ & $100(53.8)$ & \multirow[t]{2}{*}{0.031} \\
\hline Yes & $33(15.1)$ & $22(66.7)$ & $11(33.3)$ & \\
\hline \multicolumn{5}{|l|}{ Recurrence } \\
\hline No & $197(90.0)$ & $99(50.3)$ & 98 (49.7) & \multirow[t]{2}{*}{0.406} \\
\hline Yes & $22(10.0)$ & $9(40.9)$ & $13(59.1)$ & \\
\hline \multicolumn{5}{|c|}{ Histologic subtypes } \\
\hline MIA & $3(1.4)$ & $0(0.0)$ & $3(100.0)$ & \multirow[t]{3}{*}{$<0.001$} \\
\hline IA & $209(95.4)$ & $101(48.3)$ & $108(51.7)$ & \\
\hline IAV & $7(3.2)$ & $7(100.0)$ & $0(0.0)$ & \\
\hline
\end{tabular}

EGFR, epidermal growth factor receptor; pTNM, pathological Tumor-Node-Metastasis; MIA, minimally invasive adenocarcinoma; IA, invasive adenocarcinoma; IAV, invasive adenocarcinoma variant.

110 patients received chemotherapy and 109 cases underwent TKI targeted therapy (Table II).

Association between EGFR mutations and clinicopathological characteristics. Of the 219 patients, EGFR mutations were identified in 111 patients $(50.7 \%)$, including 61 cases of L858R mutations (55\%), 40 cases of 19-Del (36\%), 5 cases of L861Q (4.5\%), 3 cases of G719X (2.7\%) and 2 cases of 20-Ins (1.8\%). Double mutations were not detected. EGFR mutations were more common in females compared with males $(70.5 \%$ vs. $32.5 \%$; $\mathrm{P}<0.001)$, and the mutation rate was increased in non-smokers compared with smokers (56.4\% vs. $33.3 \%$; $\mathrm{P}=0.003)$. The EGFR mutation rate in MIA cases was significantly increased compared with IA and IAV (100\% vs. $51.7 \%$ and $0 \%$, respectively; $\mathrm{P}<0.001$ ). EGFR mutations were more common in patients with $\mathrm{T} 1$ stage tumors compared with other stages $(54.7 \%$; $\mathrm{P}=0.027)$ and in patients without vascular invasion compared with patients exhibiting vascular invasion (53.8\%; $\mathrm{P}=0.031)$.

Association between clinicopathological characteristics and survival time. A total of 151 mortalities occurred prior to 
Table II. EGFR mutation types and treatment of 219 patients.

\begin{tabular}{lcl}
\hline Mutation type & Total, no. (\%) & \multicolumn{1}{c}{ Treatment } \\
\hline Wild type & $108(49.3)$ & Chemotherapy $^{\mathrm{a}}$ \\
G719X & $3(2.7)$ & Second-line TKI $^{\mathrm{c}}$ \\
19-Del & $40(36.0)$ & First-line TKI $^{\mathrm{b}}$ \\
L858R & $61(55.0)$ & First-line TKI $^{\mathrm{b}}$ \\
L861Q & $5(4.5)$ & Second-line TKI \\
20-Ins & $2(1.8)$ & Chemotherapy $^{\mathrm{a}}$ \\
\hline
\end{tabular}

Treatment with ${ }^{a}$ cisplatin plus pemetrexed or ${ }^{b}$ gefitinib or ${ }^{c}$ afatinib. EGFR, epidermal growth factor receptor; G719X, point mutation in exon 18; 19-Del, deletion mutation in exon 19; 20-Ins, insertion mutation in exon 20; L858R and L861Q 2 base-pair substitution mutation in exon 21 .

March 30th, 2017. The mean follow-up time was 30.9 months (range, 4.7-53.8 months). The 1-, 2- and 3-year survival rates of the patients were $83.6,54.8$ and $42.9 \%$, respectively, and the median survival time (MST) was 27.2 months (data not shown). The survival time was significantly increased in female patients, patients $<60$ years-old and non-smokers compared with male patients, patients $\geq 60$ years-old and smokers (Fig. 1A-C). Patients with pTNM stage I tumors were associated with increased OS time compared with those with stage II or III tumors (39.6 months vs. 11.3 months and 10.4 months, respectively; $\mathrm{P}<0.001$; Fig. 1D). The survival time was significantly increased in patients without nerve invasion or vascular invasion or clinical recurrence compared with patients with nerve invasion or vascular invasion or clinical recurrence, respectively (Fig. 1E-G). There was no significant difference in OS time among adenocarcinoma subtypes $(\mathrm{P}=0.112$; Fig. 1H). The survival time was markedly increased in patients with EGFR mutations or 19-Del compared with patients without EGFR mutations or 19-Del (Fig. 2A and B). There was no significant difference in OS time between patients with or without the L858 mutation $(\mathrm{P}=0.074$; Fig. $2 \mathrm{C})$, or with or without other mutations of EGFR ( $\mathrm{P}=0.222$; Fig. 2D).

A total of 110 patients received cisplatin-based chemotherapy, while 109 patients received TKI targeted therapies (Table II). The present study suggested that TKI targeted therapies could prolong survival time compared with cisplatin-based chemotherapy (47.3 months vs. 15.8 months, $\mathrm{P}<0.001)$. However, there was no significant difference in terms of survival time with first- or second-line TKI treatment (45.7 months vs. 49.2 months; Fig. 1I). Cox's multiple regression analysis was used to analyze the association of various clinical characteristics and patient prognosis. Multivariate analysis revealed that tumor pTNM stage, nerve invasion, vascular invasion and EGFR mutation types were independent predictors for patient prognosis. The results also suggested that patients with the 19-Del mutation were associated with a relatively good prognosis, while patients with an L858R mutation were not (Table III).

\section{Discussion}

In the present study, EGFR mutations were detected in $111 / 219$ patients with lung adenocarcinoma (50.7\%), and the most common mutations were L858R (54.9\%) and 19-Del
(36\%), accounting for $90.9 \%$ of all EGFR mutations. Sex, age, smoking status, pTNM stage, nerve invasion, vascular invasion, EGFR mutation status, recurrence and therapeutic regimen were all associated with OS time. Multivariate analysis revealed that pTNM stage, nerve invasion, vascular invasion and EGFR mutations were independent predictors for patient prognosis.

The detection of EGFR mutations in lung adenocarcinoma patients has been widely performed worldwide $(5-7,10,21)$. A number of methods for detecting EGFR mutations now, exist, with direct sequencing and F-PCR being the most common clinically used methods (22-24). Direct sequencing can detect unknown gene mutations and is the 'gold standard' for detecting gene mutations. However, the low sensitivity, the requirement for large specimen size, the complexity and duration of the protocol, the high cost and difficult interpretation of results are disadvantages of direct sequencing $(22,23)$. The F-PCR method combines specific primers with a double loop probe technique. The amplified products are detected by double ring probes, and the mutation status of sample DNA are observed using a PCR platform, specific reaction procedures and highly specific Taq DNA polymerases $(22,24)$. This method has the advantages of high specificity and sensitivity for detecting rare mutations, a simple and rapid protocol, simple data interpretation, and suitability for large-scale screening in clinical laboratories $(22,24)$. In the present study, EGFR mutations in lung adenocarcinoma patients were detected using the F-PCR method.

The EGFR gene is located on the short arm of human chromosome 7, composed of 188,307 bases and 28 exons, and its tyrosine kinase functional domain is encoded by exons 18-24 (5). Previous studies have demonstrated that mutations in exons 18-21 in patients with lung cancer were associated with patient-responsiveness to EGFR-TKIs. This is likely due to changes in the structure of the EGFR ATP binding area, enhancing the combining capacity of EGFR-TKIs $(5,7,21)$. To date, $>30$ mutations of EGFR have been reported, including 19-Del ( $\sim 5 \%$ all EGFR mutations), L858R ( 40-45\%), G719X ( 5\%), 20-Ins ( 1\%) $(5,12,21)$. Studies have suggested that EGFR mutation rates in patients with lung adenocarcinoma differ among countries and ethnicities, between sexes, and with smoking status (25-27). The overall mutation rate of EGFR in Chinese patients with lung adenocarcinoma in the present study was $50.7 \%$, which is consistent with previous reports $(6,25-27)$. The mutation rate in female patients was significantly higher than that of male patients $(\mathrm{P}<0.001)$ while the mutation rate in smokers was low compared with non-smokers $(\mathrm{P}=0.003)$, which was also consistent with previous reports $(25,26,28)$. It was also demonstrated that EGFR mutations were more common in patients with T1 stage tumors or without vascular invasion compared with T2 stage patients, or those with vascular invasion $(\mathrm{P}=0.027$ and $\mathrm{P}=0.031$, respectively; Table I).

Previous studies have revealed that EGFR mutations are predictors of TKI treatment response and prognosis of patients with lung adenocarcinoma $(10,20,27,29)$. However, clinical studies indicated that patients with different EGFR mutations were associated with different outcomes $(10,29)$. Patients with 19-Del or L858R have been demonstrated to be associated with a relatively good prognosis following TKI treatment compared 

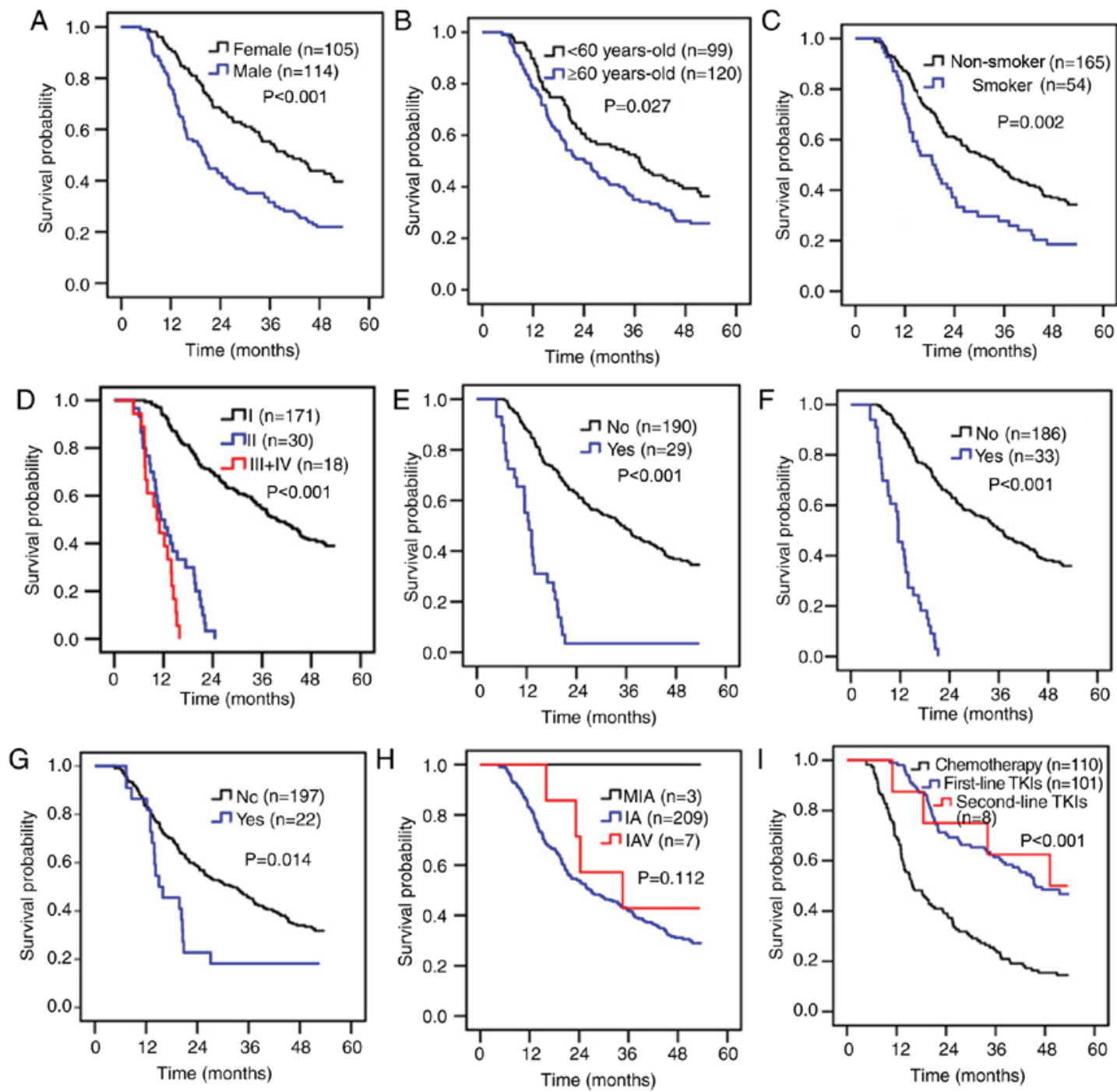

Figure 1. Survival analysis of 219 patients with lung adenocarcinoma. Analysis of the association of OS time and (A) sex, (B) age, (C) smoking history (D) pTNM stage, (E) nerve invasion status, (F) vascular invasion status, (G) clinical recurrence, (H) adenocarcinoma subtypes, and (I) post-surgical therapeutic regimen. OS, overall survival; pTNM pathological Tumor-Node-Metastasis; TKI, tyrosine kinase inhibitor; n, number.

with other mutations (5). A number of studies have suggested that 19-Del or L858R mutations do not have different effects on prognosis $(21,30)$, while others have indicated that patients with 19-Del survived significantly longer than patients with L858R (31,32). In the present study, the survival time of patients with EGFR mutations was significantly higher than patients without EGFR mutations ( $\mathrm{P}<0.001$; Fig. 2A), and multivariate analyses demonstrated that the presence of an EGFR mutation was a predictor of favorable prognosis for patients with lung adenocarcinoma $(\mathrm{P}<0.001$; Table III). These results were consistent with previous reports $(10,29)$. Patients with 19-Del were associated with an improved prognosis compared with those without (Fig. 2B; $\mathrm{P}<0.001$ ), and 19-Del was demonstrated to be a predictor of good outcome (HR, 0.463; 95\% CI, 0.241-0.889; $\mathrm{P}=0.021)$. L858R was not demonstrated to be an independent predictor of lung adenocarcinoma prognosis, although the survival time of patients with L858R was longer than those without (37.6 months vs. 24.5 months; $\mathrm{P}=0.074$; Fig. 2C). This may be associated with the differences in the sequences and structures of exons 19 and 21, and the differences in TKI activity in patients with different mutations $(33,34)$.
A number of rare EGFR mutations were also detected, including 3 cases of G719X (2.7\%), 5 cases of L861Q (4.5\%) and 2 cases of 20 -Ins $(1.8 \%)$, a rate which was consistent with previous reports $(35,36)$. Patients with G719 or L861Q had an MST of 49.2 months following second-line TKI treatment, which was longer than that of patients without G719 or L861Q mutations (49.2 months vs. 26.9 months; $\mathrm{P}=0.222$; Fig. 2D). In the present study, only 10 cases of rare mutations were detected $(9.0 \%)$, and only 8 of these patients were treated with second-line TKIs. Further larger scale studies are required.

It has been reported that $\sim 5 \%$ EGFR mutations occur in exon 20, and patients with these mutations are often insensitive to TKI treatment (37). Clinical studies have confirmed that patients with NSCLC acquired resistance to TKIs following a period of treatment. A mutation in T790M in exon 20 was detected in $\sim 50 \%$ patients with acquired resistance $(37,38)$. Other studies have demonstrated that T790M mutations existed in a minority of untreated tumor cells prior to treatment, and that the mutation rates increased significantly following treatment $(21,38)$. No T790M mutation was detected in exon 20, which may be due to all specimens being collected 

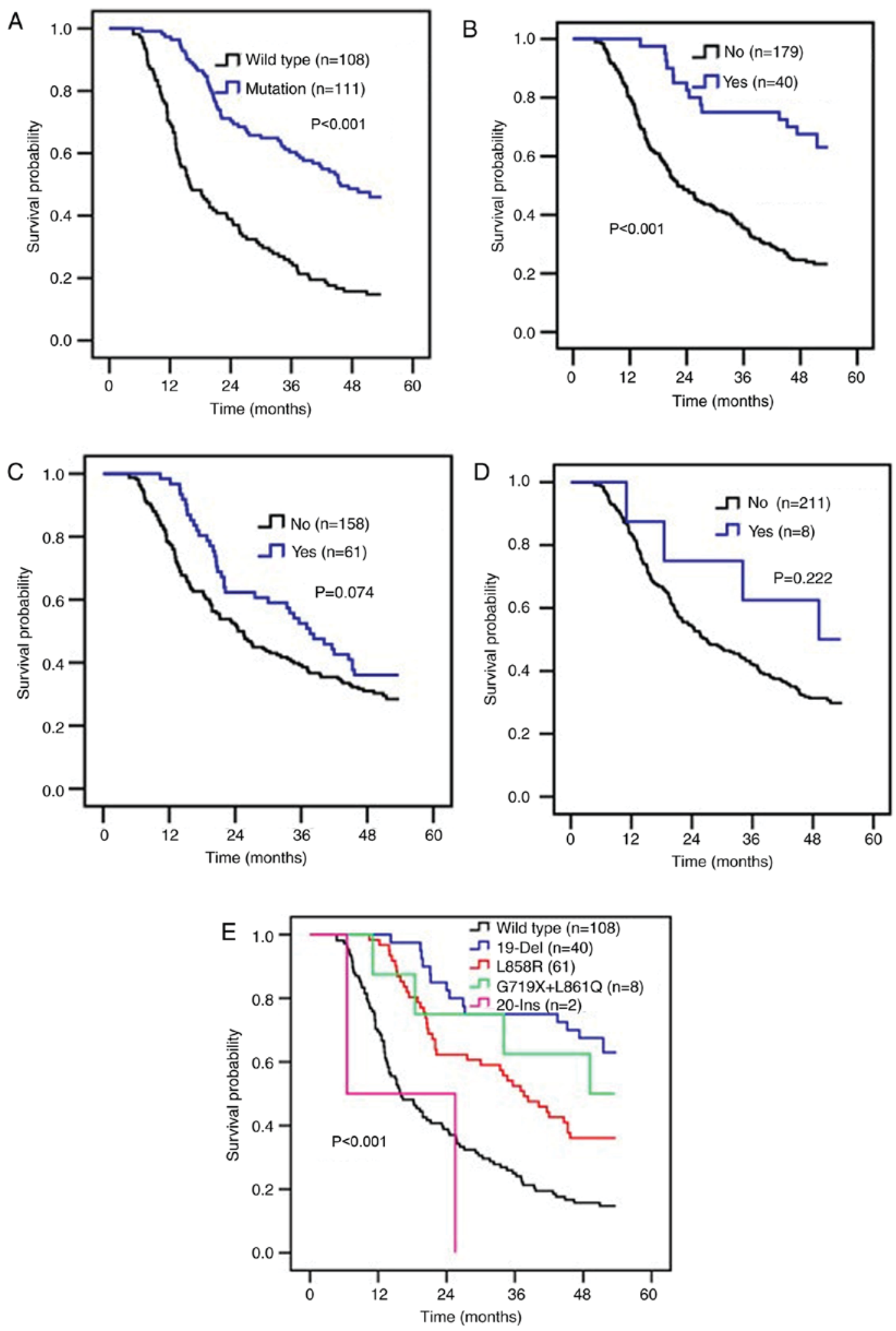

Figure 2. Kaplan-Meier survival analysis for EGFR mutation subtypes of the patients. Overall survival time for patients with or without (A) EGFR mutations, (B) 19-Del, (C) L858R, (D) rare mutations of EGFR, and (E) different EGFR mutation types. EGFR, epidermal growth factor receptor; 19-Del, deletion mutations in exon 19; L858R, base-pair substitution mutation in exon 21; n, number.

from surgical patients, or because no patients were treated with chemotherapeutic drugs prior to surgery. Alternatively, the number of tumor cells exhibiting the T790M mutation may have been too low for detection. In following studies, it is necessary to perform analyze T790M in patients with acquired drug-resistant lung adenocarcinoma.
Previous studies have indicated that IASLC/ATS/ERS classification of lung adenocarcinoma may be an independent prognostic factor $(13,15,20)$. In the present study, it was demonstrated that EGFR mutations were more common in MIA $(100 \%)$ than in IA $(51.7 \%)$ and IAV (0\%). The survival time of patients with MIA was longer than that of patients with IA and 
Table III. Univariate and multivariate analysis of clinical characteristics and the overall survival time of patients with lung adenocarcinoma.

\begin{tabular}{|c|c|c|c|c|c|c|}
\hline \multirow[b]{2}{*}{ Variable } & \multicolumn{3}{|c|}{ Univariate analysis } & \multicolumn{3}{|c|}{ Multivariate analysis } \\
\hline & Number, (MST, months) & $95 \% \mathrm{CI}$ & P-value & HR & $95 \% \mathrm{CI}$ & P-value \\
\hline \multicolumn{7}{|l|}{ Sex } \\
\hline Female & $105(40.2)$ & $29.976-50.424$ & $<0.001$ & & & \\
\hline Male & $114(19.8)$ & $16.487-23.113$ & & & & \\
\hline \multicolumn{7}{|l|}{ Age, years } \\
\hline$<60$ & $99(37.1)$ & $28.325-45.875$ & 0.027 & & & \\
\hline$\geq 60$ & $120(24.0)$ & $18.249-29.751$ & & & & \\
\hline \multicolumn{7}{|l|}{ Smoking status } \\
\hline Non-smoker & $165(34.1)$ & $26.695-41.505$ & 0.002 & & & \\
\hline Smoker & $54(18.7)$ & $12.579-24.821$ & & & & \\
\hline \multicolumn{7}{|l|}{ pTNM stage } \\
\hline I & 171 (39.6) & $32.872-46.328$ & $<0.001$ & 1 & & \\
\hline II & 30 (11.3) & $7.945-14.655$ & & 8.904 & $6.175-12.840$ & $<0.001^{\mathrm{c}}$ \\
\hline III+IV & $18(10.4)$ & $7.490-13.310$ & & & & \\
\hline \multicolumn{7}{|l|}{ Nerve invasion } \\
\hline No & $190(34.7)$ & 28.081-41.319 & $<0.001$ & 1 & & \\
\hline Yes & $29(12.6)$ & $10.358-14.842$ & & 6.692 & $3.591-12.470$ & $<0.001^{\mathrm{c}}$ \\
\hline \multicolumn{7}{|l|}{ Vascular invasion } \\
\hline No & $186(36.2)$ & $29.517-42.883$ & $<0.001$ & 1 & & \\
\hline Yes & $33(11.5)$ & $9.706-13.294$ & & 3.579 & $1.961-6.533$ & $<0.001^{\mathrm{c}}$ \\
\hline \multicolumn{7}{|l|}{ Recurrence } \\
\hline No & $197(32.3)$ & 24.899-39.701 & 0.014 & & & \\
\hline Yes & $22(15.0)$ & $8.335-21.664$ & & & & \\
\hline \multicolumn{7}{|c|}{ Histologic subtypes } \\
\hline MIA & $3(\mathrm{NR})$ & - & 0.112 & & & \\
\hline IA & 209 (26.9) & - & & & & \\
\hline IAV & $7(34.6)$ & - & & & & \\
\hline \multicolumn{7}{|l|}{ EGFR mutation } \\
\hline Wild type & $108(15.8)$ & $11.472-20.128$ & $<0.001^{\mathrm{a}}$ & 1 & & \\
\hline Mutation & $111(45.7)$ & $36.326-57.290$ & & & & \\
\hline 19-Del & 40 (NR) & - & $<0.001^{\mathrm{b}}$ & 0.432 & $0.101-1.855$ & $0.259^{\mathrm{c}}$ \\
\hline L858R & $61(37.6)$ & $29.182-46.018^{\mathrm{b}}$ & & 0.051 & $0.011-0.244$ & $<0.001^{\mathrm{c}}$ \\
\hline G719X+L861Q & $8(49.2)$ & $28.500-54.146^{\mathrm{b}}$ & & 0.110 & $0.025-0.493$ & $0.004^{\mathrm{c}}$ \\
\hline 20-Ins & $2(6.5)$ & $6.500-^{\mathrm{b}}$ & & 0.066 & $0.011-0.390$ & $0.003^{\mathrm{c}}$ \\
\hline \multicolumn{7}{|c|}{ EGFR 19-Del mutation } \\
\hline No & $179(22.2)$ & $17.853-26.547$ & $<0.001$ & 1 & & \\
\hline Yes & $40(\mathrm{NR})$ & - & & 0.463 & $0.241-0.889$ & $0.021^{\mathrm{d}}$ \\
\hline \multicolumn{7}{|c|}{ EGFR L858R mutation } \\
\hline No & $158(24.5)$ & 19.804-29.196 & 0.074 & & & \\
\hline Yes & $61(37.6)$ & $29.182-46.018$ & & & & \\
\hline \multicolumn{7}{|c|}{ EGFR rare mutatione } \\
\hline No & $211(26.9)$ & 19.906-33.894 & 0.222 & & & \\
\hline Yes & $8(49.2)$ & $29.501-52.199$ & & & & \\
\hline \multicolumn{7}{|l|}{ Treatment } \\
\hline Chemotherapy & $110(15.8)$ & $11.432-20.168$ & $<0.001$ & & & \\
\hline TKI & $109(47.3)$ & $21.500-1.711$ & & & & \\
\hline First-line & $101(45.7)$ & $21.500-1.678$ & & & & \\
\hline Second-line & $8(49.2)$ & $18.500-14.146$ & & & & \\
\hline
\end{tabular}

CI, confidence intervals; EGFR, epidermal growth factor receptor; HR, hazard ratio; pTNM, pathological Tumor-Node-Metastasis; 19-Del, deletion mutations in exon 19; L858R, base-pair substitution mutation in exon 21; MIA, minimally invasive adenocarcinoma; IA, invasive adenocarcinoma; IAV, invasive adenocarcinoma; MST, median

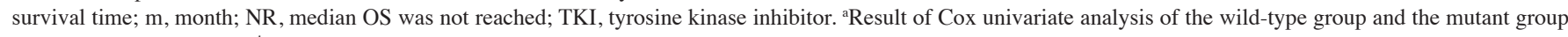
as dichotomous variables. ${ }^{\mathrm{b}} \mathrm{Cox}$ univariate analysis of wild-type, 19-Del, L858R, G719X+L861Q and 20-Ins as polytomous variables. ${ }^{\mathrm{c}} \mathrm{Results}$ of multivariable analysis with EGFR mutation types (wild-type, 19-Del, L858R, G719X+L861Q and 20-Ins) as a polytomous variable and other characteristics (including sex, age, smoking status, pTNM stage, nerve invasion, vascular invasion and recurrence) as binary variables. ${ }^{\mathrm{d}}$ Results of multivariable analysis using with or without 19 -Del mutation as a binary variable and other characteristics (including sex, age, smoking status, pTNM stage, nerve invasion, vascular invasion and recurrence) also as binary variables. eG719X and L861Q mutation types of EGFR. 
IAV, however, this was not statistically significant (26.9 months vs. 34.6 months, $\mathrm{P}=0.112$; Fig. 1I). The present study has a number of limitations: $\sim 95.4 \%$ specimens were collected from patients with IA. Furthermore, the majority of cases of lung adenocarcinoma were at an early stage. All patients who participated in the present study were treated in a single area (Yantai, China), which may cause selection bias. Furthermore, the histological categories of lung adenocarcinoma, including MIA, IA and IAV, were considered in the present study, but the histological subtypes of lung adenocarcinoma, including lepidic, acinar, papillary, micropapillary, solid and mucinous predominant subtypes, were not considered. A further study with a more even ratio of all lung adenocarcinoma subtypes and stages is required.

Sumiyoshi et al (39) indicated that nerve invasion and clinical recurrence could serve as independent predictors for patients with lung adenocarcinoma, and Matsumura et al (12) suggested that vascular invasion could also function as an independent predictor $(40,41)$. In the present study, multivariate analysis demonstrated that nerve invasion, vascular invasion and clinical recurrence were independent predictors for patients with lung adenocarcinoma (Fig. 1E-G). Previous studies have suggested that high pTNM stage is associated with poor prognosis (41-43). In the present study, high pTNM stage was associated with a relatively short survival time, and pTNM stage was demonstrated to be a predictor of prognosis (Fig. 1D).

To conclude, the present study suggests that prognosis of patients with lung adenocarcinoma is associated with pTNM staging, nerve invasion, vascular invasion and EGFR mutation status. Patients exhibiting 19-Del were associated with a good prognosis compared with those exhibiting L858R following TKI targeted therapy. Overall, the present study demonstrated that EGFR mutation detection is conducive for selecting a favorable therapeutic regimen for patients with lung adenocarcinoma.

\section{Acknowledgements}

Not applicable.

\section{Funding}

The present study was supported by the Science and Technology Program of Shandong Province (grant no. J15LK02) and the Scientific Research Project of Yantai (grant no. 2016ZH081).

\section{Availability of data and materials}

All data generated or analyzed during this study are included in this published article.

\section{Authors' contributions}

$\mathrm{XZ}, \mathrm{LC}$ and JL were major contributors toward data collection, data analysis and manuscript writing. $\mathrm{XH}, \mathrm{YZ}$ and $\mathrm{HZ}$ performed the histological examination of lung adenocarcinoma. BW, BL and PG, were responsible for manuscript preparation, study design, data analysis and article finalization. All authors read and approved the final manuscript.

\section{Ethics approval and consent to participate}

Ethics approval was granted by the Medical Ethics Committee of Binzhou Medical University (reference no. 2012-37). Written informed consent was obtained from each participant.

\section{Consent for publication}

Not applicable.

\section{Competing interests}

All authors declare that they have no competing interests.

\section{References}

1. Jia Y, Li F, Liu YF, Zhao JP, Leng MM and Chen L: Depression and cancer risk: A systematic review and meta-analysis. Public Health 149: 138-148, 2017.

2. Chen W, Zheng R, Baade PD, Zhang S, Zeng H, Bray F, Jemal A Yu XQ and He J: Cancer statistics in China, 2015. CA Cancer J Clin 66: 115-132, 2016.

3. Chen Z, Fillmore CM, Hammerman PS, Kim CF and Wong KK: Non-small-cell lung cancers: A heterogeneous set of diseases. Nat Rev Cancer 14: 535-546, 2014.

4. Devarakonda S, Morgensztern D and Govindan R: Genomic alterations in lung adenocarcinoma. Lancet Oncol 16: e342-e351, 2015.

5. Pao W and Miller VA: Epidermal growth factor receptor mutations, small-molecule kinase inhibitors, and non-small-cell lung cancer: Current knowledge and future directions. J Clin Oncol 23: 2556-2568, 2005.

6. Cho J, Choi SM, Lee J, Lee CH, Lee SM, Yim JJ, Chung DH, Yoo CG, Kim YW, Han SK and Park YS: The association of EGFR mutations with stage at diagnosis in lung adenocarcinomas. PLoS One 11: e0166821, 2016.

7. Lin JH, Lin D, Xu L, Wang Q, Hu HH, Xu HP and He ZY: The association between clinical prognostic factors and epidermal growth factor receptor-tyrosine kinase inhibitor (EGFR-TKI) efficacy in advanced non-small-cell lung cancer patients: A retrospective assessment of 94 cases with EGFR mutations. Oncotarget 8: 3412-3421, 2017.

8. Na II, Rho JK, Choi YJ, Kim CH, Park JH, Koh JS, Ryoo BY, Yang SH and Lee JC: The survival outcomes of patients with resected non-small cell lung cancer differ according to EGFR mutations and the P21 expression. Lung Cancer 57: 96-102, 2007.

9. Eichler AF, Kahle KT, Wang DL, Joshi VA, Willers H, Engelman JA, Lynch TJ and Sequist LV: EGFR mutation status and survival after diagnosis of brain metastasis in nonsmall cell lung cancer. Neuro Oncol 12: 1193-1199, 2010.

10. Isaka T, Nakayama H, Yokose T, Ito H, Miyagi Y, Matsuzaki T, Nagata M, Furumoto H, Nishii T, Katayama K, et al: Epidermal growth factor receptor mutations and prognosis in pathologic N1-N2 pulmonary adenocarcinoma. Ann Thorac Surg 102: 1821-1828, 2016.

11. Dancey JE: Epidermal growth factor receptor inhibitors in non-small cell lung cancer. Drugs 67: 1125-1138, 2007.

12. Matsumura Y, Owada Y, Yamaura T, Muto S, Osugi J, Hoshino M, Higuchi M, Ohira T, Suzuki H and Gotoh M: Epidermal growth factor receptor gene mutation as risk factor for recurrence in patients with surgically resected lung adenocarcinoma: A matched-pair analysis. Interact Cardiovasc Thorac Surg 23: 216-222, 2016.

13. Yoshizawa A, Sumiyoshi S, Sonobe M, Kobayashi M, Fujimoto M, Kawakami F, Tsuruyama T, Travis WD, Date H and Haga H: Validation of the IASLC/ATS/ERS lung adenocarcinoma classification for prognosis and association with EGFR and KRAS gene mutations: Analysis of 440 Japanese patients. J Thorac Oncol 8: 52-61, 2013.

14. Memon AA, Zhang H, Gu Y, Luo Q, Shi J, Deng Z, Ma J and Ma W: EGFR with TKI-sensitive mutations in exon 19 is highly expressed and frequently detected in Chinese patients with lung squamous carcinoma. Onco Targets Ther 10: 4607-4613, 2017. 
15. Russell PA, Barnett SA, Walkiewicz M, Wainer Z, Conron M, Wright GM, Gooi J, Knight S, Wynne R, Liew D and John T: Correlation of mutation status and survival with predominant histologic subtype according to the new IASLC/ATS/ERS lung adenocarcinoma classification in stage III (N2) patients. J Thorac Oncol 8: 461-468, 2013.

16. Sun Y, Hou L, Yang Y, Xie H, Yang Y, Li Z, Zhao H, Gao W and Su B: Two-gene signature improves the discriminatory power of IASLC/ATS/ERS classification to predict the survival of patients with early-stage lung adenocarcinoma. Onco Targets Ther 9: 4583-4591, 2016

17. Kim D, Kim HK, Kim SH, Lee HY, Cho JH, Choi YS, Kim K, Kim J, Zo JI and Shim YM: Prognostic significance of histologic classification and tumor disappearance rate by computed tomography in lung cancer. J Thorac Dis 10: 388-397, 2018.

18. Abdollah F, Sun M, Suardi N, Gallina A, Capitanio U, Bianchi M Tutolo M, Passoni N, Karakiewicz PI, Rigatti P, et al: National Comprehensive Cancer Network practice guidelines 2011: Need for more accurate recommendations for pelvic lymph node dissection in prostate cancer. J Urol 188: 423-428, 2012.

19. Travis WD, Brambilla E, Noguchi M, Nicholson AG, Geisinger K Yatabe Y, Powell CA, Beer D, Riely G, Garg K, et al: International association for the study of lung cancer/american thoracic society/european respiratory society international multidisciplinary classification of lung adenocarcinoma. J Thorac Oncol 6: 244-285, 2011.

20. Warth A, Muley T, Meister M, Stenzinger A, Thomas M, Schirmacher P, Schnabel PA, Budczies J, Hoffmann $\mathrm{H}$ and Weichert W: The novel histologic International Association for the Study of Lung Cancer/American Thoracic Society/European Respiratory Society classification system of lung adenocarcinoma is a stage-independent predictor of survival. J Clin Oncol 30: 1438-1446, 2012

21. Mok TS, Wu YL, Thongprasert S, Yang CH, Chu DT, Saijo N, Sunpaweravong P, Han B, Margono B, Ichinose Y, et al: Gefitinib or carboplatin-paclitaxel in pulmonary adenocarcinoma. N Engl J Med 361: 947-957, 2009.

22. Angulo B, Conde E, Suárez-Gauthier A, Plaza C, Martínez R, Redondo P, Izquierdo E, Rubio-Viqueira B, Paz-Ares L, Hidalgo M, et al: A comparison of EGFR mutation testing methods in lung carcinoma: Direct sequencing, real-time PCR and immunohistochemistry. PLoS One 7: e43842, 2012.

23. Wang J, Cai Y, Dong Y, Nong J, Zhou L, Liu G, Su D, Li X, Wu S, Chen X, et al: Clinical characteristics and outcomes of patients with primary lung adenocarcinoma harboring ALK rearrangements detected by FISH, IHC, and RT-PCR. PLoS One 9: e101551, 2014.

24. Kim EK, Kim KA, Lee CY and Shim HS: The frequency and clinical impact of HER2 alterations in lung adenocarcinoma. PLoS One 12: e0171280, 2017.

25. Shi Y, Au JS, Thongprasert S, Srinivasan S, Tsai CM, Khoa MT, Heeroma K, Itoh Y, Cornelio G and Yang PC: A prospective, molecular epidemiology study of EGFR mutations in Asian patients with advanced non-small-cell lung cancer of adenocarcinoma histology (PIONEER). J Thorac Oncol 9: 154-162, 2014.

26. Midha A, Dearden S and McCormack R: EGFR mutation incidence in non-small-cell lung cancer of adenocarcinoma histology: A systematic review and global map by ethnicity (mutMapII). Am J Cancer Res 5: 2892-2911, 2015.

27. Martin P, Shiau CJ, Pasic M, Tsao M, Kamel-Reid S, Lin S, Tudor R, Cheng S, Higgins B, Burkes R, et al: Clinical impact of mutation fraction in epidermal growth factor receptor mutation positive NSCLC patients. Br J Cancer 114: 616-622, 2016.

28. Wei WE, Mao NQ, Ning SF, Li JL, Liu HZ, Xie T, Zhong JH, Feng Y, Wei CH and Zhang LT: An analysis of EGFR mutations among 1506 cases of non-small cell lung cancer patients in Guangxi, China. PLoS One 11: e0168795, 2016.

29. Won YW, Han JY, Lee GK, Park SY, Lim KY, Yoon KA, Yun T, Kim HT and Lee JS: Comparison of clinical outcome of patients with non-small-cell lung cancer harbouring epidermal growth factor receptor exon 19 or exon 21 mutations. J Clin Pathol 64 947-952, 2011

30. Lai Y, Zhang Z, Li J, Sun D, Zhou Y, Jiang T, Han Y, Huang L, Zhu Y, Li X and Yan X: EGFR mutations in surgically resected fresh specimens from 697 consecutive Chinese patients with non-small cell lung cancer and their relationships with clinical features. Int J Mol Sci 14: 24549-24559, 2013.
31. Riely GJ, Pao W, Pham D, Li AR, Rizvi N, Venkatraman ES, Zakowski MF, Kris MG, Ladanyi M and Miller VA: Clinical course of patients with non-small cell lung cancer and epidermal growth factor receptor exon 19 and exon 21 mutations treated with gefitinib or erlotinib. Clin Cancer Res 12: 839-844, 2006

32. Lee VH, Tin VP, Choy TS, Lam KO, Choi CW, Chung LP, Tsang JW, Ho PP, Leung DK, Ma ES, et al: Association of exon 19 and 21 EGFR mutation patterns with treatment outcome after first-line tyrosine kinase inhibitor in metastatic non-small-cell lung cancer. J Thorac Oncol 8: 1148-1155, 2013.

33. Gazdar AF and Minna JD: Inhibition of EGFR signaling: All mutations are not created equal. PLoS Med 2: e377, 2005.

34. Carey KD, Garton AJ, Romero MS, Kahler J, Thomson S, Ross S, Park F, Haley JD, Gibson N and Sliwkowski MX: Kinetic analysis of epidermal growth factor receptor somatic mutant proteins shows increased sensitivity to the epidermal growth factor receptor tyrosine kinase inhibitor, erlotinib. Cancer Res 66: 8163-8171, 2006.

35. Beau-Faller M, Prim N, Ruppert AM, Nanni-Metéllus I,Lacave R, Lacroix L, Escande F, Lizard S, Pretet JL, Rouquette I, et al: Rare EGFR exon 18 and exon 20 mutations in non-small-cell lung cancer on 10117 patients: A multicentre observational study by the French ERMETIC-IFCT network. Ann Oncol 25: 126-131, 2014.

36. Watanabe S, Minegishi Y, Yoshizawa H, Maemondo M, Inoue A, Sugawara S, Isobe H, Harada M, Ishii Y, Gemma A, et al: Effectiveness of gefitinib against non-small-cell lung cancer with the uncommon EGFR mutations G719X and L861Q. J Thorac Oncol 9: 189-194, 2014.

37. Zhang Q, Ke E, Niu F, Deng W, Chen Z, Xu C, Zhang X, Zhao N, Su J, Yang J, et al: The role of T790M mutation in EGFR-TKI re-challenge for patients with EGFR-mutant advanced lung adenocarcinoma. Oncotarget 8: 4994-5002, 2017.

38. Su KY, Chen HY, Li KC, Kuo ML, Yang JC, Chan WK, Ho BC, Chang GC, Shih JY, Yu SL and Yang PC: Pretreatment epidermal growth factor receptor (EGFR) T790M mutation predicts shorter EGFR tyrosine kinase inhibitor response duration in patients with non-small-cell lung cancer. J Clin Oncol 30: 433-440, 2012

39. Sumiyoshi S, Yoshizawa A, Sonobe M, Kobayashi M, Fujimoto M, Tsuruyama T, Date H and Haga H: Pulmonary adenocarcinomas with micropapillary component significantly correlate with recurrence, but can be well controlled with EGFR tyrosine kinase inhibitors in the early stages. Lung Cancer-J Iaslc 81: 53-59, 2013.

40. Ohtaki Y, Shimizu K, Kakegawa S, Nagashima T, Nakano T, Atsumi J,Enokida Y,Igai H,Ibe T, Sugano M, et al: Postrecurrence survival of surgically resected pulmonary adenocarcinoma patients according to EGFR and KRAS mutation status. Mol Clin Oncol 2: 187-196, 2014.

41. Li J, Yang X, Xia T, Guan Y and Zhong N: Stage I synchronous multiple primary non-small cell lung cancer: CT findings and the effect of TNM staging with the 7th and 8th editions on prognosis. J Thorac Dis 9: 5335-5344, 2017.

42. Ramlau R, Krawczyk P, Dziadziuszko R, Chmielewska I, Milanowski J, Olszewski W, Stencel K, Ramlau-Piątek K, Segiet A, Skroński M, et al: Predictors of EGFR mutation and factors associated with clinical tumor stage at diagnosis: Experience of the INSIGHT study in Poland. Oncol Lett 14: 5611-5618, 2017.

43. Saji H, Tsuboi M, Shimada Y, Kato Y, Yoshida K, Nomura M, Matsubayashi J, Nagao T, Kakihana M, Usuda J, et al: A proposal for combination of total number and anatomical location of involved lymph nodes for nodal classification in non-small cell lung cancer. Chest 143: 1618-1625, 2013.

This work is licensed under a Creative Commons Attribution-NonCommercial-NoDerivatives 4.0 International (CC BY-NC-ND 4.0) License. 